\title{
PENGENDALIAN KUALITAS PRODUK CACAT BATANG ALUMUNIUM EC GRADE MENGGUNAKAN PENDEKATAN FAILURE MODE AND EFFECT ANALYSIS
}

\author{
Dita Meidiarti \\ Teknik Industri, Fakultas Sains dan Teknologi, Universitas Al-Azhar Indonesia \\ e-mail: dithmeyidyarti@gmail.com
}

\begin{abstract}
ABSTRAK
Dalam dunia industri kualitas produk adalah salah satu faktor yang paling penting untuk suatu produk. PT Tembaga Mulia Semanan, Tbk adalah perusahaan Manufacture yang bergerak dalam pembuatan batang alumunium. Terdapat kendala pada saat proses produksi berlangsung yaitu, seperti produk yang cacat yang diakibatkan oleh beberapa faktor yang dapat terjadi. Untuk meminimalisir produk batang Alumunium Ec Grade yang cacat maka peneliti melakukan analisa dengan menggunakan tools pengendalian kualitas. Dengan menggunakan pendekatan Failure Mode Effect and Analysis (FMEA), maka dapat diidentifikasi risiko kegagalan apa yang dapat menyebabkan produk menjadi cacat. Berdasarkan hasil penelitian yang telah dilakukan bahwa batang Aluminum Ec grade memiliki risiko kegagalan yang menyebabkan produk menjadi cacat dengan menggunakan metode Failure Mode Effect and Analysis (FMEA) menunjukkan bahwa pada kategori Machine memiliki Risk Priority Number (RPN) terbesar dengan nilai sebesar 36.
\end{abstract}

Kata kunci: failure mode effect and analysis, fishbone diagram, pengendalian kualitas.

\begin{abstract}
In the industrial world product quality is one of the most important factors for a product. PT Tembaga Mulia Semanan, Tbk is a Manufacture company which is engaged in manufacturing aluminum rods. There are obstacles when the production process takes place, such as defective products caused by several factors that can occur. To minimize the defective Aluminum Grade Ec rod products, the researchers conducted an analysis using quality control tools. By using the Failure Mode Effect and Analysis (FMEA) approach, the risk of failure can be identified which can cause the product to become defective. Based on the results of research that has been done that Aluminum Ec grade bars have a risk of failure that causes the product to become defective using the Failure Mode Effect and Analysis (FMEA) method, showing that the Machine category has the largest Risk Priority Number (RPN) with a value of 36.
\end{abstract}

Keywords: failure mode effect and analysis, fishbone diagram, quality control.

\section{PENDAHULUAN}

Industri merupakan salah satu upaya untuk meningkatkan kesejateraan penduduk. Selain itu industrialisasi juga tidak terlepas dari usaha untuk meningkatkan mutu sumberdaya manusia dan kemampuan untuk memanfaatkan sumber daya alam secara optimal. Umumnya Industri manufaktur menggunakan bahan-bahan baku utama untuk membuat suatu produk diambil dari alam seperti tanaman, air, hewan, tumbuhan dan material yang didapat dari perut bumi. Seperti halnya bahan baku Almunium yang didapat dari dalam perut bumi yang biasanya diolah menjadi batangan Alumuniun yang diguakan sebagai dasar pembuatan kabel listrik rumah tangga, nantinya akan diproses dan ditambahkan beberapa bahan lainnya untuk menjadi sebuh produk dengan standar yang telah ditetapkan perusahaan. Dalam dunia industri kualitas produk adalah salah satu faktor yang paling penting untuk produk yang dihasilkan. Produk yang dihasilkan nantinya akan masuk ke dalam tahap pengendalian kualitas (Quality control). Untuk menghasilkan produk-produk tersebut PT. Tembaga Mulia Semanan. Tbk, sangatlah mengutamakan kualitas dari produk yang dihasilkan. Namun terkadang terdapat kendala pada saat proses produksi berlangsung yaitu, seperti produk yang cacat, produk yang cacat atau reject diakibatkan oleh beberapa faktor yang dapat terjadi. 


\section{Dita Meidiarti}

Semakin tingginya permintaan batang Alumunium menjadikan perusahaan PT. Tembaga mulia semanan Tbk mengejar produksinya untuk memenuhi kebutuhan permintaan customer, namun selama proses produksi terdapat kendala yang dihadapi yaitu seperti hasil produksi yang reject. Dalam analisa untuk memperbaiki Quality Control terhadap produk reject tersebut maka penelitian ini menggunakan metode Peta Control, Fishbone Diagram dan Failure Mode and Effect Analysis (FMEA) dengan metode tersebut diharapkan dapat mengetahui penyebab masalah pada produk reject dan sehingga nantinya dapat meminimalisir produk yang reject. Penelitian sebelumnya, analisis pengendalian kualitas dilakukan dalam upaya mengendalikan tingkat kerusakan produk dengan menggunakan alat bantu statistik [1], dengan pendekatan Six Sigma dan Analisis Kaizen Serta New Seven Tools [2,3,4]. Penggunaan FMEA juga dilakukan dalam mengidentifikasi resiko kegagalan [5,6], melakukan analisis pengendalian kualitas dengan pendekatan proses [7], analisis kualitas produk [8], analisis produktivitas mesin [9], dan analisis beban kerja [10], maka pengunaan aplikasi FMEA terus di kembangkan dalam analisis pengendalian kualitas [11].

\section{METODE PENELITIAN}

Pengumpulan data dilakukan di PT. Tembaga Mulia Semanan, Tbk selama dua bulan di unit Alumunium Businss Unit, teknik pengambilan data yang dilakukan adalah dengan cara observasi secara langsung ke lapangan, wawancara dan juga dokumentasi. Peneliti melakukan pengambilan atau pengumpulan data berupa company profile, produk reject (cacat) batangan Alumunium Ec Grade, pengumpulan data dengan cara observasi dilakukan untuk mengumpulkan data produk cacat dengan mengamati lini finish good. Untuk pengumpulan data dengan wawancara dilakukan untuk mendapatkan informasi data dalam penyebab terjadinya kegagalan dalam produk reject dengan menggunakan metode Fishbone Diagram dan Failure Mode Effect and Analysis (FMEA) serta untuk pembobotan severity, occurance, dan detection. Sedangkan untuk pengumpulan data dengan cara dokumentasi digunakan untuk meminta data-data yang diperlukan untuk dilakukan pengolahan data.

Setelah melakukan pengumpulan data selanjutnya peneliti melakukan pengolahan data dengan menggunakan tools Pengedalian Kualitas. Tools Pengendalain Kualitas pertama yang digunakan yaitu, Peta Kendali Atribut digunakan untuk mengetahui propersi produk cacat batangan Alumunium Ec Grade apakah ada produk cacat ada yang keluar batas kendali kontrol atau tidak. Untuk Fishbone Diagram digunakan untuk mengetahui faktor-faktor apa saja yang menyebabkan produk menjadi reject (cacat) dan apa sebab dan akibat dari faktor-faktor yang ada terhadap produk reject (cacat) tersebut. Sedangkan Failure Mode and Effect Analysis (FMEA) digunakan dalam pengolahan data yaitu untuk mengetahui apa potensi, akibat, cara penanggulanga serta rekomendasi aksi yang terjadi terhadap faktor-faktor kategori, sehingga dengan metode ini diharapkan dapat mengetahui penyebab terjadinya produk reject (cacat) sehingga dapat meminimalisir akan terjadinya produk reject (cacat). Analisis data yang diguanakan pada penelitian ini adalah teknik pengembangan. Karena analisis data pada penelitian ini mencakup prosedur organisasi data, reduksi, dan penyajian data baik dengan tabel, bagan atau grafik. Kemudian data diklasifikasikan berdasarkan jenis dan komponen yang dikembangkan. Serta data yang dianalisis secara deskriptif maupun dalam bentuk perhitungan kuantitatif.

\section{HASIL DAN PEMBAHASAN}

Dalam penelitian ini data produk cacat yang digunakan adalah jumlah produk cacat batangan Alumunium Ec Grade dengan 2 tipe yang di produksi selama 2 bulan pada bulan April dan Mei, yaitu batangan Alumunium Ec Grade jenis Rod yang memiliki total cacat 
sebanyak $17,573 \mathrm{~kg}$ dan jenis Castbar yang memiliki total cacat sebanyak $17,177 \mathrm{~kg}$. Dari data produk cacat tersebut akan digunakan oleh peneliti sebagai bahan input yang kemudian akan di proses dengan menggunakan pengolahan data berupa Peta Control, Fishbone dan Failure Mode and Effect Analysis (FMEA). Data di bawah ini adalah data jumlah produk cacat pada produksi batangan Aluunium Ec Grade pada bulan april dan bulai Mei 2018.

Tabel 1. Data Produk Cacat Pada Dua Bulan

\begin{tabular}{|c|c|c|c|}
\hline \multirow{2}{*}{ Bulan } & \multirow{2}{*}{ Tanggal } & \multicolumn{2}{|c|}{ Jenis Cacat } \\
\hline & & Rod & Cast Bar \\
\hline \multirow{21}{*}{ April } & 1 & 446 & 525 \\
\hline & 2 & 98 & 230 \\
\hline & 3 & 277 & 435 \\
\hline & 4 & 225 & - \\
\hline & 10 & 665 & 529 \\
\hline & 11 & 303 & 533 \\
\hline & 12 & 397 & 211 \\
\hline & 13 & 1,269 & 1,468 \\
\hline & 14 & 399 & 224 \\
\hline & 15 & 889 & 353 \\
\hline & 16 & 290 & - \\
\hline & 17 & 307 & 473 \\
\hline & 18 & 222 & - \\
\hline & 19 & 771 & 3,844 \\
\hline & 20 & 770 & 1,545 \\
\hline & 21 & 306 & - \\
\hline & 22 & 750 & 348 \\
\hline & 23 & 383 & 638 \\
\hline & 24 & 804 & 685 \\
\hline & 25 & 1,007 & 733 \\
\hline & 26 & 72 & - \\
\hline \multirow{9}{*}{ Mei } & 6 & 1,840 & 1,240 \\
\hline & 7 & 402 & 980 \\
\hline & 8 & 155 & - \\
\hline & 9 & 135 & 134 \\
\hline & 15 & 373 & 417 \\
\hline & 16 & 2,508 & 318 \\
\hline & 17 & 133 & 263 \\
\hline & 18 & 389 & - \\
\hline & 19 & 952 & 1,051 \\
\hline \multicolumn{2}{|c|}{ Total } & 17,537 & 17,177 \\
\hline
\end{tabular}

\section{Peta Kontrol P}

Setelah mengumpulkan data produk cacat batangan Alumunium Ec Grade tipe Rod dan Catsbar selanjutnya akan diolah dengan menggunakan metode peta kendali untuk melihat apakah produk cacat tersebut masih ada didalam batas kendali atau berada diluar batas kendali standar. Dalam pengamatan untuk menguji sampel dengan peta $\mathrm{P}$, peneliti mengambil sampel sebanyak 30 sample. Dengan melihat pada Tabel 2 dapat diketahui bahwa nilai CL yang didapatkan adalah sebesar 0.0150, sedangkan nilai LCL terkecil didapatkan nilai -0.02 dan nilai UCL terbesar didapatkan nilai 0.08. Dari data tersebut 
Pengendalian Kualitas Produk Cacat Batang Alumunium Ec Grade Menggunakan Pendekatan Failure Mode And Effect Analysis

\section{Dita Meidiarti}

dapat dibuat grafik yang menggambarkan seberapa besar proporsi cacat produk yang telah diuji, seperti terlihat pada Gambar 1.

Tabel 2. Pengolahan Data Menggunakan Peta Kendali P

\begin{tabular}{|c|c|c|c|c|c|c|c|}
\hline Bulan & Tanggal & $\begin{array}{c}\text { Jumlah } \\
\text { Produksi }\end{array}$ & $\begin{array}{c}\text { Jumlah } \\
\text { Cacat }\end{array}$ & $\mathbf{p}$ & CL & UCL & LCL \\
\hline \multirow{21}{*}{ April } & 1 & 64,760 & 971 & 0.0150 & 0.0150 & 0.08 & (0.05) \\
\hline & 2 & 60,020 & 328 & 0.0055 & 0.0055 & 0.05 & (0.03) \\
\hline & 3 & 61,608 & 712 & 0.0116 & 0.0116 & 0.07 & $(0.05)$ \\
\hline & 4 & 2,962 & 225 & 0.0760 & 0.0760 & 0.22 & $(0.07)$ \\
\hline & 10 & 54,919 & 1,194 & 0.0217 & 0.0217 & 0.10 & (0.06) \\
\hline & 11 & 61,342 & 836 & 0.0136 & 0.0136 & 0.08 & $(0.05)$ \\
\hline & 12 & 59,964 & 608 & 0.0101 & 0.0101 & 0.07 & $(0.04)$ \\
\hline & 13 & 56,136 & 2,737 & 0.0488 & 0.0488 & 0.17 & (0.07) \\
\hline & 14 & 60,089 & 623 & 0.0104 & 0.0104 & 0.07 & $(0.05)$ \\
\hline & 15 & 57,066 & 1,242 & 0.0218 & 0.0218 & 0.10 & $(0.06)$ \\
\hline & 16 & 58,947 & 290 & 0.0049 & 0.0049 & 0.04 & (0.03) \\
\hline & 17 & 67,868 & 780 & 0.0115 & 0.0115 & 0.07 & $(0.05)$ \\
\hline & 18 & 61,173 & 222 & 0.0036 & 0.0036 & 0.04 & $(0.03)$ \\
\hline & 19 & 39,906 & 4,615 & 0.1156 & 0.1156 & 0.29 & (0.06) \\
\hline & 20 & 53,678 & 2,315 & 0.0431 & 0.0431 & 0.15 & $(0.07)$ \\
\hline & 21 & 48,096 & 306 & 0.0064 & 0.0064 & 0.05 & $(0.04)$ \\
\hline & 22 & 57,675 & 1,098 & 0.0190 & 0.0190 & 0.09 & (0.06) \\
\hline & 23 & 59,956 & 1,021 & 0.0170 & 0.0170 & 0.09 & $(0.05)$ \\
\hline & 24 & 64,066 & 1,489 & 0.0232 & 0.0232 & 0.11 & $(0.06)$ \\
\hline & 25 & 67,629 & 1,740 & 0.0257 & 0.0257 & 0.11 & $(0.06)$ \\
\hline & 26 & 63,519 & 72 & 0.0011 & 0.0011 & 0.02 & $(0.02)$ \\
\hline \multirow{9}{*}{ Mei } & 6 & 44,335 & 3,080 & 0.069 & 0.069 & 0.21 & $(0.07)$ \\
\hline & 7 & 63,179 & 1,382 & 0.022 & 0.022 & 0.10 & (0.06) \\
\hline & 8 & 67,629 & 155 & 0.002 & 0.002 & 0.03 & $(0.02)$ \\
\hline & 9 & 58,578 & 269 & 0.005 & 0.005 & 0.04 & $(0.03)$ \\
\hline & 15 & 56,537 & 790 & 0.014 & 0.014 & 0.08 & $(0.05)$ \\
\hline & 16 & 57,046 & 2,826 & 0.050 & 0.050 & 0.17 & $(0.07)$ \\
\hline & 17 & 59,029 & 396 & 0.007 & 0.007 & 0.05 & $(0.04)$ \\
\hline & 18 & 56,436 & 389 & 0.007 & 0.007 & 0.05 & $(0.04)$ \\
\hline & 19 & 59,608 & 2,003 & 0.034 & 0.034 & 0.13 & $(0.07)$ \\
\hline
\end{tabular}

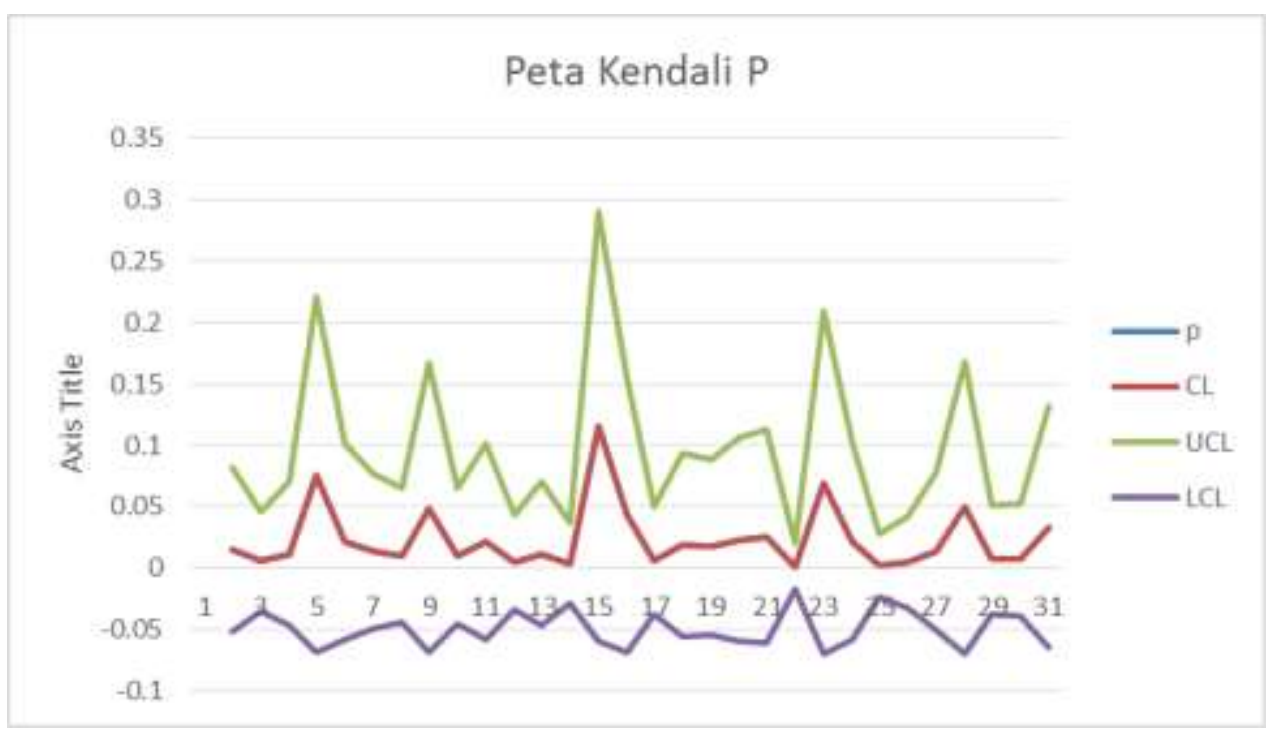

Gambar 1. Grafik Peta Kendali P 
Dari grafik di atas yang telah diolah dapat disimpulkan bahwa tidak ada proporsi cacat yang keluar dari batas UCL maupun LCL. Artinya bahwa produk telah diproduksi dengan cukup baik sehingga tidak ada proporsi cacat atau jumlah cacat yang keluar dari batas UCL maupun LCL.

\section{Fishbone Diagram}

Untuk permasalahan pada produk cacat yang terjadi pada pembuatan batang Alumunium jenis Rod, kemudian untuk mngetahui sebab-akibat mengapa produk tersebut paling banyak mengalami cacat (reject) maka peneliti melakukan observasi menggunakan fishbone diagram, yang dapat dilihat pada Gambar 2.

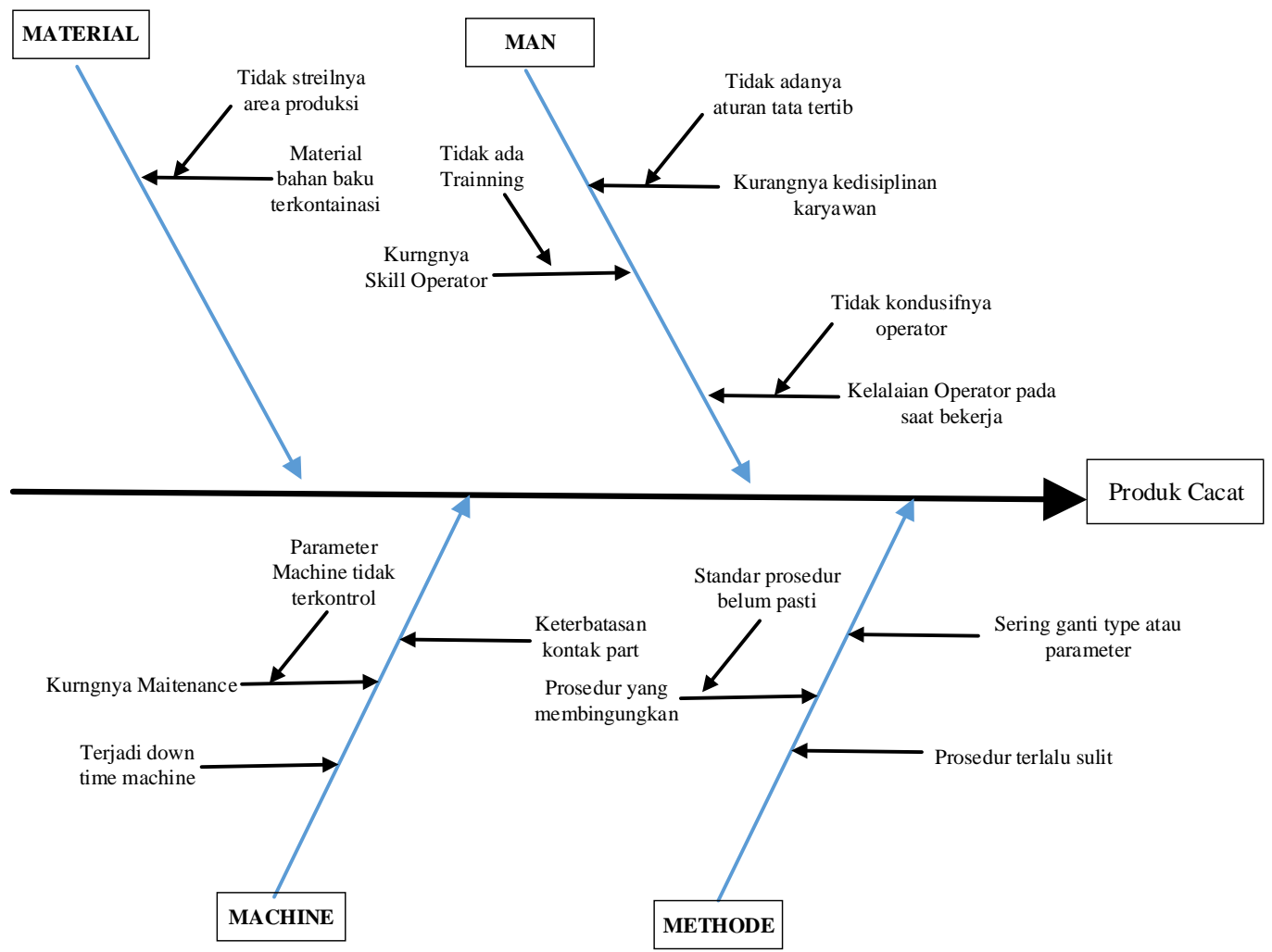

Gambar 2. Hasil Diagram Fishbone Untuk Produk Cacat Batangan Almuium Jenis Rod

Akar faktor-faktor masalah yang terjadi pada produk batangan Alumunium Ec Grade menjadi cacat (reject) pada jenis rod dikarenakan faktor man, machine, material dan method.

\section{Failure Mode Effect and Analysis (FMEA)}

Penitian selanjutnya dilakukan dengan meggunakan metode Failure Mode Effect and Analysis (FMEA) metode ini digunakan untuk dapat meminimalisir serta mengidentifikasi kegagalan dalam suatu pembuatan produk sehingga produk tersebut dapat cacat (reject). Berikut tabel dibawah adalah hasil analisis yang didapat dengan nilai severity, occurent, dan detection didapatkan oleh hasil wawancara dengan pakar di PT. Tembaga Mulia Semanan Tbk. Dari hasil penelitian menggunakan metode Failure Mode and Effect Analysis (FMEA) telah dianalisis bahwa nilai Risk Priority Number (RPN) terbesar adalah pada kategori Machine dengan nilai sebessar 36 untuk itu maka peneliti melakukan recommend untuk melakukan maintenance mesin dengan secara berkala agar proses produksi tidak terhambat dan tidak berpengaruh terhadap hasil produksi dengan tidak ada 
Pengendalian Kualitas Produk Cacat Batang Alumunium Ec Grade Menggunakan Pendekatan Failure Mode And Effect Analysis

\section{Dita Meidiarti}

kecacatan produk rod yang signifikan. Tabel 3 menunjukkan hasil FMEA untuk kecacatan produk batangan Alumunium Ec Grade rod

Tabel 3. Hasil Worksheet (FMEA) untuk kecacatan produk batangan Alumunium Ec

\begin{tabular}{|c|c|c|c|c|c|c|c|c|c|}
\hline Kategori & Potential Failure Mode & Potential Effect Failure & Severity & $\begin{array}{c}\text { Potential Cause } \\
\text { Mechanism of Failure }\end{array}$ & Occurent & t $\begin{array}{c}\text { Current Process Control } \\
\text { Prevention }\end{array}$ & Detectio & RPN & Recommended \\
\hline \multirow{3}{*}{ Man } & Bekerja tidak sesuai SOP & $\begin{array}{l}\text { Tidak disiplin mengikuti } \\
\text { aturan }\end{array}$ & 2 & Kurangnya pemahaman & 2 & $\begin{array}{l}\text { Mengadakan Sosialisai secara } \\
\text { berkala }\end{array}$ & 3 & 12 & $\begin{array}{l}\text { Mengadakan Pelatihan } \\
\text { dan sosiaisasi saat KYT }\end{array}$ \\
\hline & Kurangnya skill operator & $\begin{array}{l}\text { Belum dapat melakukan } \\
\text { pekerjaan secara maksimal }\end{array}$ & 2 & $\begin{array}{l}\text { Proses produksi } \\
\text { terhambat }\end{array}$ & 1 & Mengadakan pelatihan & 3 & 6 & $\begin{array}{l}\text { Melakukan Pelatihan } \\
\text { secara berkala }\end{array}$ \\
\hline & Kelelahan bekerja & Tidak fokus dalam bekerja & 3 & $\begin{array}{l}\text { Pekerjaan menjadi tidak } \\
\text { optimal }\end{array}$ & 3 & Bekerja secara TIM & 3 & 27 & $\begin{array}{l}\text { Beromunikasi dengan } \\
\text { Foreman }\end{array}$ \\
\hline Machine & $\begin{array}{l}\text { Parameter Machine tidak } \\
\text { terkontrol }\end{array}$ & $\begin{array}{l}\text { Terdapat keterbatasan } \\
\text { Contact Part }\end{array}$ & 5 & $\begin{array}{l}\text { Menghasilkan produk } \\
\text { yang tidak sesuai }\end{array}$ & 2 & Melakukan repair stock & 2 & 20 & $\begin{array}{l}\text { Harus mengontrol } \\
\text { ketersediaan stock spare }\end{array}$ \\
\hline Material & $\begin{array}{l}\text { Bahan baku } \\
\text { terkontaminasi (sow } \\
\text { mould) }\end{array}$ & $\begin{array}{l}\text { Tecampurnya bahan baku } \\
\text { dengan material lain }\end{array}$ & 2 & $\begin{array}{l}\text { Mengakibatkan produk } \\
\text { wire putus (inclusi) }\end{array}$ & 2 & $\begin{array}{l}\text { Melakukan sterilisasi area bak } \\
\text { sow mould }\end{array}$ & 2 & 8 & $\begin{array}{l}\text { Tidak membuang sampah } \\
\text { material apapun kedalam } \\
\text { Membuat SOP }\end{array}$ \\
\hline
\end{tabular}

\section{KESIMPULAN}

Dari hasil penelitian terhadap pengendalian kualitas produk batangan Alumunium Ec Grade didapatkan bahwa tidak ada proporsi cacat yang keluar dari batas UCL maupun LCL. Artinya bahwa produk telah diproduksi dengan cukup baik sehingga tidak ada proporsi cacat atau jumlah cacat yang keluar dari batas UCL maupun LCL atau batas kontrol standar perusahaan. Produk cacat (reject) batangan Alumunium Ec grade yang paling banyak memiliki kecacatan produk yaitu jenis Rod 17,573 kg dan jenis Castbar yang memiliki total cacat sebanyak 17,177 kg. Akar faktor-faktor masalah yang terjadi pada produk batangan Alumunium Ec Grade menjadi cacat (reject) pada jenis rod karena faktor man, machine, material dan methode. Risiko kegagalan dalam proses pembuatan produk batangan Alumunium Ec Grade sehingga mengakibatkan produk cacat (reject) yaitu pada kategori Machine, dilihat pada metode Failure Mode Effect and Analysis (FMEA) memiliki Risk Priority Number (RPN) terbesar dengan nilai 36.

\section{DAFTAR PUSTAKA}

[1] Faiz, "Analisis Pengendalian Kualitas Produksi Di PT. Masscom Grahpy Dalam Upaya Mengendalikan Tingkat Kerusakan Produk Menggunakan Alat Bantu Statistik".Skripsi, Semarang: Fakultas Ekonomi Universitas Diponegoro, 2010.

[2] Rukmana,. dan P. Wisnubroto, "Pengendalian Kualitas Produk Dengan Pendekatan Six Sigma Dan Analisis Kaizen Serta New Seven Tools Sebagai Usaha Pengurangan Kecacatan Produk". Jurnal Teknologi, Vol. 8. No. 1, Juni 2015.

[3] Sakti,. dan Cyrilla Indri Parwati. (2012). "Pengendalian Kualitas Produk Cacat Dengan Pendekatan Kaizen Dan Analisis Masalah Dengan Seven Tools". Prosiding Seminar Nasional Aplikasi Sains \& Teknologi (SNAST) Periode III, 3 November 2012 ISBN: 1979-911X. Yogyakarta.

[4] Suprianto,. dan Astin Tiara Pratiwi Sunardi. (2015). "Pengendalian Kualitas Produk Pada Proses Produksi Rib A320 Di Sheet Metal Forming Shop” INDEPT, Vol. 5, No. 2, pp.6-15, Juni 2015.

[5] Martanto, dan N. B. Puspitasari. "Penggunaan FMEA Dalam Mengidentifikasi Resiko Kegagalan Proses Produksi Sarung Atm (Alat Tenun Mesin) (Studi Kasus Pt. Asaputex Jaya Tegal)'’. Skripsi, Semarang: Fakultas Teknik, Universitas Diponegoro, 2014.

[6] W. Kosasih, Adianto, Erickson." Analisis Pengendalian Kualitas Produk Bucket Tipe ZX 200 Gp Dengan Metode Statistical Process Control Dan Failure Mode and 
EffectAnalysis (Studi Kasus: PT. CDE), Jurnal Ilmiah Teknik Industri, Vol. 3 No. 2 , pp.85-93, Juni 2015.

[7] X. Zhao, "A Process Oriented Quality Control Approach Based On Dynamic Spc And FMEA Repository", International Journal of Industrial Engineering, Vol. 18 Issue 8, pp.444-451, 2011.

[8] B.B. Korda, C.P Ningrum, S. Alexander, L.L Salomon,"Analisis Kualitas Produk Drum Dan Metal Packaging (Studi Kasus: Plant 1 PT Guna Senaputra Sejahtera)", Jurnal Ilmiah Teknik Industri, Vol. 7 No. 3, pp. 149-159, 2019.

[9] A. Rahman dan S. Perdana," Analisis Produktivitas Mesin Percetakan Perfect Binding Dengan Metode OEE Dan FMEA”, Vol. 7, No. 1, 34-42, 2019.

[10] Z.A Yasmin, dan S. Ariyanti Analisis Beban Kerja Pada Maintenance BD-Check Dengan Metode Full Time Equivalent, Jurnal Ilmiah Teknik Industri, Vol. 6 No. 1, pp. 55-62, 2018.

[11] Paciarotti, C., Mazzuto, G. and D'Ettorre, D., "A revised FMEA application to the quality control management", International Journal of Quality \& Reliability Management, Vol. 31 No. 7, pp. 788-810, 2014. 